\title{
The Effect of Fundamental Risk of Listed Companies on the Market Pricing of Accruals Quality
}

\author{
-Base on the Data of Shanghai's Non-Financial Industry
}

\author{
Zhaoyuan Geng, Zhendong Wang, Tian Song, Tingjun Liu,Wenting Chi, Yue Yu, Lufei Wang, \\ Tong Zhang, Chaoying He, Minjie Wang, Yiyang Zheng, Yipeng Zhu, Gengen Zhou, Tiantian Li
}

Department of Applied Economics, Business School of Zhejiang University City College, Hangzhou, China.

Email: gengzy@zucc.edu.cn

Received 2013

\begin{abstract}
Motivated by the theoretical results of Yee (2006), with accruals quality, the author of this paper studied enterprises' earnings quality management, and analyzed the effect of accruals quality on capital cost, which is rising with the increase of basic risks, and extended and applied to his study the theoretical study of Francis, LaFond, Olsson and Schipper et al .
\end{abstract}

Keywords: Cost of Capital; Accruals Quality; Earnings Quality; Fundamental Risk

\section{Introduction}

Yee defined Fundamental Risk as "uncertainty in future dividend payments" [1]. No studies were found published in recent domestic literatures specialized in fundamental risk. Quite a few studies are carried out based on information risk to probe into earnings quality, the level of earning management and the behavior of manipulating profit. Accrued item quality is known as Accruals Quality. The conception of accruals was presented by Healy in 1985. With the conception of accruals in a narrow sense, he measured controllable accruals, and using accruals amount to express earnings quality [2]. In a certain sense, accrual basis of accounting can be regarded as a potential balance of cost and efficiency , which between a system of submitting cash flow only and a system that reveals adequately (Beaver, 1998) .

Regarding the definition of AQ (AQ, Accruals Quality), it is the expression of Dechow and Dichv that make AQ become more and more important in choosing accounting procedure, which clear the conception of AQ as well.

Whether Accruals Quality can be a risk pricing factor to explain the excessive rate of return of shares, no final conclusion has yet been reached on this matter [3]. Studies about Accruals Quality in Chinese literature mainly lay there weight on researching from the angles of company management, motivation of contrast and the behavior of earning management in company during financing, including IPO of quoted companies, the issue of ad- ditional stocks and allotment[4] , while few people have paid attention to asset pricing of Accrual Quality mentioned above.

\section{Hypothesis and Sample Selection}

\subsection{Conclusion Hypothesis}

Yee studied the relationship between earnings quality and equity risk premium. Equity risk premium is the component of cost of capital. Mode Yee is based on information (including noise) backgrounds in the reports revealed by venture firms that the inventors rely on. Earnings quality means an earning evaluation mistake which is modifiable but unpredictable [5]. Yee researched into Accruals Quality in 2006. The research results indicates that income quality risk has no influence on cost of capital when there is no fundamental risk, and the increasing fundamental risk will make income quality risk expend its influence on cost of capital.

We analyze the research results of Yee and come up with an experiential research direction: how does the relationship between earning quality risk and cost of capital rely on fundamental risk, so I suggest the first conclusion hypothesis:

H1: earning quality risk will magnify its influence on cost of capital, with increasing fundamental risk.

\subsection{Hypothesis and Sample Selection}


This article takes balance sheet approach to calculate business accruals, which leads to the second hypothesis in this article.

H2: This article is based on the empirical data of non-financial business in Shanghai stock exchange.

Considered that Collins and Hriban's think CFO calculated in balance sheet approach will lead to more noise and biased results in the mode, the data before 1998 is ignored. In the meanwhile, enterprises started to carry out new Accounting Standards for Business Enterprises after the year of 2006, short-term investments in the formula for calculating business accruals are replaced by trading financial assets. The samples in this article are strictly constrained in the companies which have complete data during ten years.

\section{Determination of Earnings Quality Risk and Fundamental Risk}

\subsection{Take Accruals Quality as the Criteria of Earnings Quality Risk}

Yee used the method of Francis and others evaluate modificatory the mode of Dechow and Dichiev. In Dechow and Dichiev mode, DD offered a new method to estimate Accruals Quality, which is the matching degree between business accruals and the acknowledgement of cash flow. Accruals Quality is used for determining working capital of operating cash flow in the past, present and future, controlling earning variations and the level of total assets, factories, equipment and other fixedassets. Mode evaluated by Yee is as follows:

$$
\begin{gathered}
T C A_{j, t}=\phi_{0, t}+\phi_{1, j} C F O_{j, t-1}+\phi_{2, j} C F O_{j, t} \\
+\phi_{3, j} C F O_{j, t+1}+\phi_{4, j} \Delta \operatorname{Re} v_{j, t} \\
+\phi_{5, j} P P E_{j, t}+v_{j, t} \\
A Q_{j, t}=\sigma\left(v_{j, t}\right) \\
\hat{v}_{j, t}=T C A_{j, t}-\hat{\phi}_{0, j}-\hat{\phi}_{1, j} C F O_{j, t-1}-\hat{\phi}_{2, j} C F O_{j, t}-\hat{\phi}_{3, j} C F O_{j, t+1}-\hat{\phi}_{4, j} \Delta R e v_{j, t}-\hat{\phi}_{5, j} P P E_{j, t}
\end{gathered}
$$

where $T C A_{j, t}$ signifies business accruals; CFO signifies cash flow from operating activities; $\operatorname{Re} v_{j, t}$ signifies variation of sales revenue; $P P E_{j, t}$ signifies variation of fixed assets; $A Q$ signifies Accruals Quality, which expressed in the standard deviation of residual error of mode.

\subsection{The Criteria of Fundamental Risk}

Yee conceptualized Fundamental Risk as the uncertainty of unsolved future dividend payments. Since that enterprise value was considered as present value of future expected dividend, the uncertainty of unsolved future dividend payments accordingly turns into uncertainty of enterprise value [5]. However, the concept of fundamental risk is closed to the definition of information risk from Jiang Lee and Zhang. They defined information risk as the uncertainty of enterprise value or the degree that enterprise value can be evaluated by senior investors [4]. The empirical research is the risk substitute in the relevant researches of Jiang, Lee and Zhang. Jiang, Lee and Zhang made use of the uncertainty of information, led to four risk substitutes: the age of enterprise; variation of returns; trade turnover; average lasting time of cash flow in the enterprise. However, I still preserve market capitalization, the age of enterprise, variation of returns and trade turnover.I make the analysis of principal component to combine the four remain substitutes with fundamental risk. The first principal component of these four risk substitutes is combined with market capitalization. The age of enterprise, variation of returns, trade turnover are similar to $45 \%$ of total sample value which is close to the four components. The average of second, third and fourth component is approximately $18 \%$.

\section{The Empirical Research and Results}

In the empirical part, this article takes two methods to test the relationship between Accruals Quality and cost of capital of non-financial business in Shanghai stock exchange under different risk levels: asset pricing determination; take advantage of the ratio of income to price to determine cost of capital, research into the relationship between Accruals Quality and cost of capital, then make further studies on how does fundamental risk influence the ratio of Accruals Quality to income price. I made descriptive statistics of samples before starting these two determinations. This article chooses the data of non- inancial quoted companies in A share market from the year of 1999 to 2009 as samples, which has already excluded the quoted companies without complete financial data. It gets 6840 samples eventually.

\subsection{The Asset Pricing Test}

1) Sharpe's One-way Analysis of Variance

$$
\begin{aligned}
R_{j, t}-R_{F, t}= & \beta_{0}+\beta_{1}\left(R_{m, t}-R_{F, t}\right)+\beta_{2} \text { AQFactor }_{i} \\
& +\beta_{3} \text { AQFactor } * \text { FRisk }+v_{j, t}
\end{aligned}
$$

Fama-French Three-Factor Model

$$
\begin{aligned}
R_{j, t}-R_{F, t} & =\alpha_{0}+\alpha_{1}\left(R_{m, t}-R_{F, t}\right)+\alpha_{2} \text { SMB }_{t} \\
& +\alpha_{3} \text { HML }_{t}+\alpha_{4} \text { AQFactor }_{i} \\
& +\alpha_{5} \text { AQFactor }^{*} \text { FRisk }_{t}+\varepsilon_{j, t}
\end{aligned}
$$

where $R_{j, t}-R_{F, t}$ is the additional market profit in month t; $S M B_{t}$ is the difference in profit between small- scale company and large-scale company in month $\mathrm{t}$; $H M L_{t}$ is the difference in profit between 
low-market-share company and high-market-share company in month $\mathrm{t}$; AQFactor ${ }_{i}$ is rebalance loop of regulating dynamical towards hedge portfolio of monthly income difference.Since FRisk ranges between 0 to 1 , AQFactor refers to the relationship between accrual quality and cost of capital in the company with the lowest FRisk, while AQFactor*FRisk refers to the difference between accrual quality and cost of capital in the company with the lowest FRisk and the company with the highest FRisk. Suppose that the relationship between accrual quality and cost of capital is based on fundamental risk, Equation represent the positive correlation coefficients $\beta$ and $\alpha$ separately as stated in assumption 1.Model Yee indicates that non-systematic risk of earnings quality has no influence on cost of capital as non-systematic fundamental risk does. Since AQFactor refers to difference in surplus between high accruals quality investment combination and low accruals quality investment combination, and non-systematic risk of accrual quality should have no extra surplus, AQFactor stands for systematic risk of accrual quality. In fact FRisk can be hardly divided into systematic and nonsystematic parts and is regarded as non-systematic risk, so coefficient AQFactor*FRisk tends to 0.

\section{2) Empirical findings}

Panel A in Table 1 provide all the coefficients and specific regression and inspection average t. However, Gow, Ormazabal and Taylor evaluated the process of capital pricing and finded that it exaggerates excessively $t$ test values, the basis of cross section Adjustment of cluster related to annual regression coefficients. The consequence of Adjust of the cluster is similar to it. As a result, most of the relevant inspection values $t$ decrease and the values $t$ interaction with it increase. Therefore, data in Panel A is not discussable and we focus on the result in Panel B.

Column"1", "2" and "3" in Table 1 report the testing results of single factor model, where Column"1" and "2" provide the testing results of Francis and others which we use to compare. In column " 2 ", AQFactor has a strong positive correlation with $R_{j, t}-R_{F, t}$, while in column " 3 " the correlation becomes negative $(\mathrm{t}=-8.45)$. Aqfactor*FRisk is also strongly positively correlated with $R_{j, t}-R_{F, t}$ (t is 39.16). Moreover, with FRisk ranging from 0 to 1 , AQFactor(-0.233) measures the relationship between AQFactor and the income of a company with the the lowest fundamental risk, while AQFactor and $n$

Table 1. Capital pricing test of accruals quality, future income of stocks, and fundamental risk, 1999-2009.

\begin{tabular}{|c|c|c|c|c|c|c|c|}
\hline \multicolumn{8}{|c|}{ Panel A. Fama-Macbeth Regressions by Firm } \\
\hline & \multirow{2}{*}{$\begin{array}{l}\text { Predic-ted } \\
\text { Sign }\end{array}$} & \multicolumn{3}{|c|}{ CAPM } & \multicolumn{3}{|c|}{ Fama-French Three-Factor Model } \\
\hline & & 1 & 2 & 3 & 4 & 5 & 6 \\
\hline $\mathrm{Rm}-\mathrm{Rf}$ & + & 1.066 & 0.838 & 0.842 & 1.012 & 0.946 & 0.946 \\
\hline SMB & + & & & & 0.888 & 0.509 & 0.512 \\
\hline HML & + & & & & 0.218 & 0.357 & 0.356 \\
\hline AQfactor & + & & 0.812 & -0.199 & & 0.612 & -0.439 \\
\hline Aqfactor*FRisk & + & & & 1.51 & & & 1.52 \\
\hline Adj.R*R & & 0.114 & 0.149 & 0.154 & 0.158 & 0.175 & 0.179 \\
\hline
\end{tabular}

Panel B. Fama-Macbeth Regressions by Year

\begin{tabular}{|c|c|c|c|c|c|c|c|}
\hline & \multirow{2}{*}{$\begin{array}{l}\text { Predic-ted } \\
\text { Sign }\end{array}$} & \multicolumn{3}{|c|}{ CAPM } & \multicolumn{3}{|c|}{ Fama-French Three-Factor Model } \\
\hline & & 1 & 2 & 3 & 4 & 5 & 6 \\
\hline $\mathrm{Rm}-\mathrm{Rf}$ & + & 1.027 & 0.863 & 0.863 & 1.189 & 0.918 & 0.894 \\
\hline SMB & + & & & & 0.867 & 0.55 & 0.497 \\
\hline HML & + & & & & 0.436 & 0.204 & 0.202 \\
\hline AQfactor & + & & 0.812 & -0.223 & & 0.393 & -0.473 \\
\hline Aqfactor*FRisk & + & & & 1.812 & & & 1.814 \\
\hline Adj.R*R & & 0.082 & 0.095 & 0.109 & 0.098 & 0.101 & 0.114 \\
\hline
\end{tabular}

Notes: CAPM is Capital Asset Pricing Model. The samples include the stock incomes at least 18 times per month and data from 5967 companies from 1999 to 2009. The definitions of variables as follow: RM-RF is the extra return on investment of market investment combination; SMB is the investment combination income that is hedging with big or small factors of Fama-French. AQfactor is the income of the accural quality investment combination; FRisk is the first chief factor of the four agencies of which information is uncertain. Panel A reports the averange evalution coefficients and conse- 
quences of regression-anlysing only owned by 5967 companies, while Panel B provides the average evalution coefficients and the consequence regression-analysed per 25 year.

Aqfactor * FRisk measures the relationship betwee AQFactor and the income of a company with the highest fundamental risk.The testing results of Fama-French Three-Factor Model are displayed in Column"4", "5" and "6", where Column"4" and "5" reports the testing results of Francis and others, and the Column " 6 " reflects the interacted model of AQFactor and RiskScore. Being (-9.63) in Column”5”, AQFactor changes to (-9.35). Aqfactor $*$ FRisk is positively correlated with $R_{j, t}-R_{F, t}$ and extremely notable(39.18). In this regression analysis, we can find that when AQFactor decreases, both SMB and HML decreases from 0.867 to 0.550 and from 0.436 to 0.204 . This means FRisk has little influence on SMB and HML.

If AQ has a strong influence on profit when FRisk is very high instead of low, we can predict boldly that Aqfactor*FRisk and AQFactor are both positively correlated with $R_{j, t}-R_{F, t}$. To study whether the hypothesis talked about above, is connected some unusual changes or AQFactor and nonspecific econometrics affecting factors of index variables, we evaluate the regression of every value of FRisk in the model except the Aqfactor*FRisk. Figure 1. shows the regression of 10 points of AQFactor. In this figure, AQFactor increase only when FRisk increases, and the lowest value is below 0. Moreover, Figure 1 suggests that the relationship between AQFactor and FRisk are nonlinear.

\subsection{Regression test: Estimation of Cost of Capital by Using Earning-Price Ratio}

The study of Core, Guay and Verdi suggests that the result of asset pricing test by using factor model is able to prove the difference in the same period among the earnings, and those earnings are related with the factors in the models[6].However, this relation between earings and factors cannot guarantee a premium return. And in order to be scientifically rigorous, another test will be used to evaluate the relationship between AQ and cost of capital. In 1992, Alford has proved that industrial matching is benefit for controlling the difference between risk and growth, this means IndEP is able to control other decisive factors of earning-price ratio. In order to study how fundamental risk influences the relationship between earning-price ratio and accruals quality, we make regression of IndEP of growth, AQ, FRisk and AQ*FRisk. Results are displayed in Table 2.

There are three variables including Growth, AQ and FRisk in Column"1", "2" and “3" of Table 2. factor growth is significant (-1.89), which indicates that IndEP relaying on dependent variable is effective in controlling differences of growth. As is shown in the results of re- search by Francis, factor AQ is positively correlated with he cost of capital, and significant differences (-3.66) can Coefficients on AQFactor by FRisk Decile $R_{j, t}-R_{F, t}=\alpha_{0}+\alpha_{1}\left(R_{m, t}-R_{F, t}\right)+\alpha_{2} S M B_{t}+\alpha_{3} H_{M L}+\alpha_{4}$ AQFactor $_{t}+\varepsilon_{j, t}$

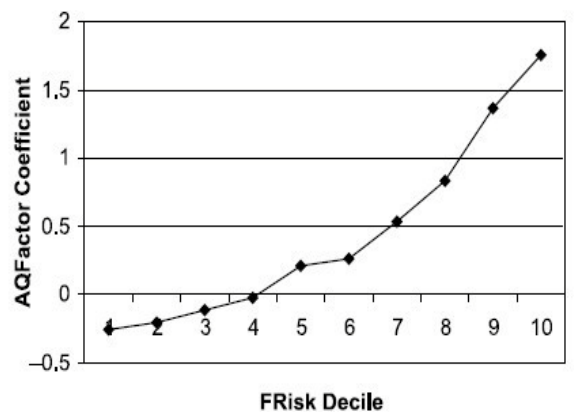

Figure 1. FRisk Decile and AQfactor.

Table 2. regression estimation of relationship between accruals quality and cost of capital (testing with IndEP) and between fundamental risk and cost of capital.

\begin{tabular}{lccccc}
\hline & $\begin{array}{c}\text { Predicted } \\
\text { Sign }\end{array}$ & $\mathbf{1}$ & $\mathbf{2}$ & $\mathbf{3}$ & $\mathbf{4}$ \\
\hline Growth & - & -0.0044 & -0.0041 & -0.0029 & -0.0025 \\
AQ & + & 0.008 & 0.0015 & 0.011 & 0.0036 \\
FRisk & + & 0.0197 & 0.0126 & & \\
Risk1 & + & & & 0.0034 & 0.0041 \\
Risk2 & + & & & 0.0149 & 0.0074 \\
AQ*FRisk & + & & 0.0157 & & \\
AQ*FRisk1 & + & & & & -0.0018 \\
AQ*FRisk2 & + & & & & 0.0166 \\
R*R & & 0.017 & 0.019 & 0.015 & 0.016 \\
\hline
\end{tabular}

Notes: Risk1 and Risk2 are the first two important index of ten risk indexes. This table provides average annual evaluating coefficient of independent variables, which originated from IndEP. T test values is standard error based on annual coefficient evaluation.

t be found. This also corresponds with the negative correlation between AQ and cost of capital. Before the regression estimation, the value of $A Q$ is decimal fraction within the range from 0 to 1 . FRisk is also positively correlated with the cost, and there are also significant differences (-3.79) . Consequently, the value of FRisk, 0.0197 , reflects the differences between the cost of capital of 1.97 percent of enterprises with the highest AQ and those of 1.97 percent of enterprises with the lowest AQ. Although both AQ and FRisk (t equals 3.66 and 3.79 separately) have significant differences, the value of FRisk is more than twice the value of AQ (1.79\% VS $0.80 \%$ ), which indicates that FRisk is an important index when determining cost of capital.Row "2" of TABLE II shows the testing results when $\mathrm{AQ}^{*}$ FRisk is added to regression estimation, where $\mathrm{AQ}$ and FRisk are allowed 
to be different. Under this circumstance, both $\mathrm{AQ}$ and FRisk decrease causing by this change. However, FRisk still has significant differences ( $t-3.01)$, while AQ does not ( $\mathrm{t}-0.51)$.AQ*FRisk positively correlated with cost of capital and the value is about 10 percent $(-1.75)$. The summation of $\mathrm{AQ}$ and $\mathrm{AQ} *$ FRisk signifies the value of the differences of cost of capital. This demonstrates that risk of earnings quality will have larger influence on cost of capital with the increase of FRisk.These factors including the age of enterprise, variations in return, volume of trade consisting of FRisk may related to AQ. In fact, the relationship between FRisk and AQ is significant. The thesis that FRisk has no significant relevance to AQ will be confirmed in the next section.

\subsection{The Methods of Fundamental Risk Test}

1) FRisk test: FRisk test corresponds with the Yee's fundamental risk test in concept. Moreover, return wave and the volume of trade is market dependent variable affected by accruals quality. Accordingly, we use the other 10 dependent variables based on Francis, LaFond, Olsson and Schipper, including two operating risk index: cash flow and standard deviation of sales volume. Hribar and Nichols find that these two operating index are connected with the accruals quality obtained from accruals quality model residual error.

2) Fundamental risk disintegrated by component analysis

We analyse two risks by using component analysis to reduce risk variable(as showed in Table 2). The first principal component of 10 proxy variables of fundamental risk are Size, Sd(CFO) and Opcycle, and the second are SD(sales volume), leverage ratio and Negearm[7]. Similar to fundamental risk, the two components are both decimal fractions ranging from 0 to 1 . Consequently, fundamental risks are Risk1 and Risk2 in Table 2.

To study the sensibility of the testing results to fundamental risk, we make the regression of IndEP of growth, AQ, Risk1, Risk2, AQ* FRisk1 and AQ* FRisk2. The Column"3" in Table 2 displays independent variable: growth, AQ, Risk1 and Risk2. As mentioned before, AQ conforms the principles that accruals quality is negative correlated with cost of capital. Cost of capital is substitute of Risk1 and Risk2 in fundamental risk. What is funny is that Risk1 has no significant differences(-0.91), while Risk2 is significantly positively correlated $(0.0149$, -6.82). This means Risk1 refers to nonsystematic risk which is not market-priced, and Risk2 refers to the systematic fundamental risk which is market-priced.

In Column"4" of Table 2, regression analysis of AQ* FRisk1 and $\mathrm{AQ}^{*}$ FRisk2 is carried out, allowing that $\mathrm{AQ}$ is different from Risk1 and Risk2. This change leads to decrease of $\mathrm{AQ}$ and Risk2 and increase of Risk1. Al- though Risk1 still has significant differences(-2.93), AQ has no significant differences(-0.52). Interacted coefficient AQ*FRisk2 is positively correlated with cost of capital and has significant differences(-4.66). Moreover, in this regression analysis, Risk1 and AQ*FRisk1 possess no significant differences.

\section{Other Regression Estimation: Implicit Cost of Capital}

The result of the study by Easton and Monahan, Guay, Kothari and Shu, suggested that the cost of capital calculated by earning-price ratio has weak relationship with the Yield To Maturity(YTM). In this section, we method to estimate cost of capital will be adopted to study the sensibility of the testing results in Section III. In this method, several indexes of implicit cost of capital will rise and thus diminish the measurement errors. Referring to the research method of Dhaliwal, Heitzman and Li, cost of capital will be calculated using discount rate implied within different applying methods of Residual Returns Value Model.

\subsection{Four Value Models}

1) Gebhardt, Lee and Swaminathan Model

Gebhardt, Lee and Swaminathan Model is used to estimate Enterprise Value:

$$
\begin{aligned}
P_{t}= & B_{t}+\sum_{t=1}^{11} \frac{F R O E_{t+1}-r_{g l s}}{\left(1+r_{g l s}\right)} B_{t+i-1} \\
& +\frac{F R O E_{t+12}-r_{g l s}}{r_{g l s}\left(1+r_{g l s}\right)^{11}} B_{t+11}
\end{aligned}
$$

where $r_{g l s}$ : cost of capital; $B$ : amount at the beginning of year; FROE : earnings forecasts

2) Claus and Thomas Model

$$
\begin{aligned}
P_{t}= & B_{t}+\sum_{t=1}^{5} \frac{F E P S_{t+i}-r_{c t} B_{t+i-1}}{\left(1+r_{c t}\right)} B_{t+i-1} \\
& +\frac{\left(F E P S_{s}-r_{c t} B_{4}\right)(1+g)}{\left(r_{c t}-g\right)\left(1+r_{c t}\right)^{5}}
\end{aligned}
$$

where $r_{c t}$ : cost of capital; FEPS : earnings forecasts of per share in the first two years, or forecasts of long-term growth rates in the following three years.

\section{3) Gode and Mohanranm Model}

Gode and Mohanranm Model which based on Earnings Growth Model by Ohlson and Juettner-Nauroth Model is as follows:

$$
r_{g m}=A+\sqrt{A+\frac{F E P S_{t+1}}{P_{t}}\left(g_{2}\left(r_{f}-0.03\right)\right)}
$$




$$
\begin{aligned}
A & =0.5\left[\left(r_{f}-0.03\right)\right]+0.5\left(D^{D P S_{t+1}} / P_{t}\right) a n d g_{2} \\
& =\frac{\left(\text { FEPS }_{t+2}-\text { FEPS }_{t+1}\right)}{F E P S_{t+1}}
\end{aligned}
$$

Easton Model DPSt is the dividend per share during period t. Assume that DPSt equals to DPS0, and the definitions of the other variables are the same as that mentioned above. Thus, Easton Model that separated from Earnings Growth Model is as follows: where the definitions of variables are the same as that mentioned above.

$$
P_{t}=\frac{F E P S_{t+2}+r_{p e g} D P S_{t+1}-F E P S_{t+1}}{r_{p e g}^{2}}
$$

\subsection{Analysis of Results}

In the calculation, each of four averages of cost of capital is evaluate, thus we gain a single cost of capital estimate: AvgCOC[13]. Compared with the results of regression estimation of IndEP, AvgCOC requires more precise data, so the sample size should be diminished from 6840 to 5967.

The estimating results based on AvgCOC are as shown in Table 3, where the data in Row " 4 " are the same as those in Row "4" of Table 2.There are three independent variables in Row "1" of Table 3: Growth, Accruals Quality (AQ) and Fundamental Risk (Frisk). According to Table 3, AQ is positively correlated with the cost, and significant differences (-6.93) can be found between four models. This also corresponds with the negative correlation between AQ and cost. The value, 0.0115 , reflects the difference between the costs of capital of 1.15 percent of enterprises with the highest AQ and those of 1.15 percent of enterprises with the lowest AQ. This value is farther higher than 0.008 in Table 2. Moreover, Frisk is positively correlated with the cost and there is also significant differences $(-13.40)$ between four models. The value of Frisk is 0.0392, which is more higher than 0.0197 in Table 2. In Row " 2 " of Table 3 , a related variable ( ${ }^{*}$ Frisk) is added, , where AQ and Frisk are allowed to be different. As a result shown in Row "2", decrease can be found in both AQ and Frisk causing by this

Table 3. Regression Analysis of the relationship between cost of stock (estimated by implicit cost of average capital)

\begin{tabular}{|c|c|c|c|c|c|}
\hline Risk2 & + & & & 0.0264 & 0.0232 \\
\hline AQ*FRisk & + & & 0.0133 & & \\
\hline AQ*FRisk1 & + & & & & 0.0026 \\
\hline AQ*FRisk2 & + & & & & 0.0081 \\
\hline $\mathrm{R} * \mathrm{R}$ & & 0.167 & 0.171 & 0.147 & 0.151 \\
\hline
\end{tabular}
and Accruals Quality and Fundamental risk.

\begin{tabular}{lccccc}
\hline & $\begin{array}{c}\text { Predicted } \\
\text { Sign }\end{array}$ & $\mathbf{1}$ & $\mathbf{2}$ & $\mathbf{3}$ & $\mathbf{4}$ \\
\hline Growth & - & -0.0284 & -0.0282 & -0.0231 & -0.0231 \\
AQ & + & 0.0115 & 0.0071 & 0.0085 & 0.0038 \\
FRisk & + & 0.0392 & 0.0332 & & \\
Risk1 & + & & & 0.0231 & 0.022 \\
\hline
\end{tabular}

change.In Row "3" and "4", Frisk is used to replace the other index of fundamental risk: Risk1 and Risk2. As a result in Row "3", Risk1 and Risk2 are systematic fundamental risks that are market-priced, opposed to the results in Table 2.

\section{Conclusion}

In this article, two sets of tests have been taken to study the effect of Fundamental Risk on the Market Pricing of Accruals Quality: Firstly, using asset-pricing determination to estimate the relationship between present worth of income and Accruals Quality. Secondly, using priceincome ratio to estimate cost of capital, meanwhile studying the fundamental risk's influence on the relationship between Accruals Quality and price-income ratio. Tests suggests that, there is no internal connecting link between Accruals Quality and cost of capital which is calculated by the present worth of income of low- fundamental-risk enterprises. However, the interaction between Accruals Quality and fundamental risk connects closely with cost of capital. And when this interaction exists, the main influence from Accruals Quality will disappear. In the final result, we can conclude that, as fundamental risk rises, Accruals Quality's influence on cost of capital is enhanced, but this influence on cost of capital of any enterprises will never exceed that of low-fundamental-risk enterprises. In fact, our results do not correspond with that of Yee about whether the risk of Earnings Quality is systematic or not. Yee found that cost of capital is related with systematic risk of Earnings Quality but not with nonsystematic risk of Earnings Quality.But in this study, it is the total risk of Earnings Quality that we focus on, and we do not divide the total risk into two separated parts, so the further study may be a huge challenge. Finally, however, we can conclude in this study that fundamental risk actually affects the relationship between Earnings Quality and cost of capital. And this suggests that total risk of Earnings Quality at least has systematic parts within it. Because if all risk of capital were not systematic, no relationship will be discovered between Earnings Quality and cost of capital, nor will any changes take place as fundamental risk change.

\section{REFERENCES}

[1] Yee, K. K. Earnings Quality and the Equity Risk Premium: 
A Benchmark Model.Contemporary, Accounting Research, 2006, 23 (Fall): 833-877.

[2] Healy P M. The Effect of Bonus Schemes on Accounting Decisions [J]. Journal of Accounting and Economics, 1985, 7, (1-3):85-107.

[3] Francis J, La Fond R, Olsson P, Schipper K. The Market Pricing of Accruals Quality [J]. Journal of Accounting and Economics, 2005, 39(2):295-327.

[4] Nichols C. Fundamental or Information Risk. An Analysis of the Earnings Quality Factor [R]. Ithaca: Cornell University, 2006.

[5] Hribar, P., and D. C. Nichols. The Use of Unsigned Earnings Quality Measures in Tests of Earnings Management. Journal of Accounting Research, 2007, 45 (December): 1017-1053.

[6] Core J E, Guay W R, Verdi R S. Is Accruals Quality a Priced Risk Factor? [J]. Journal of Accounting and Economics, 2008, 46, (1):2-22. 